\section{VERTEBRATE REMAINS IN THE CAVERNS OF GRIMALDI.}

PROF. MARCELLIN BOULE has completed his studies of the remains of vertebrate animals found with primitive man in the caverns of Grimaldi, and the final results of his work have just been published as the concluding part (fasc. iv.) of the first volume of the Prince of Monaco's “Les Grottes de Grimaldi (Baoussé-Roussé)." The new instalment deals with the Carnivora, Insectivora, Cheiroptera, and Rodentia, and various fragments of birds and lower vertebrates, and ends with a valuable general summary. Besides the technical descriptions of the fossils, illustrated by beautiful plates in heliogravure, Prof. Boule continually introduces short discussions of the relationships and distribution of the various animals with which he deals, adding several maps and some genealogical diagrams. He has therefore produced a most interesting and readable treatise on the European Pleistocene vertebrate fauna, which we commend to the notice of both geologists and zoologists. $\mathrm{He}$ specially emphasises the importance of the discovery that in the low latitude of the south coast of France there is the same succession of Pleistocene mammalian faunas that has already been observed throughout the rest of Central and Western Europe. In the bottom layers on the floor of the caverns of Grimaldi there are the animals of the warm Chellean episode (Elephas antiquus, Rhinoceros Mercki, hippopotamus, etc.); in the next layers is the cold fauna of the Acheulian and Mousterian (glutton, ermine, marmot, reindeer, etc.); in the upper layers are the ordinary mammals of historic times. Among the animals now described Prof. Boule considers he can recognise every gradation between the Pliocene bears and the modern brown bear; he also sees some approach to a Pliocene species in the Pleistocene leopard. He agrees with other observers that the wild cat most nearly approaches that of Africa, now named Felis ocreata. Equally interesting is his account of the fossil lynx, which proves to be exactly intermediate between the northern and the Spanish races of the lynx at the present day.

\section{APPARATUS FOR VAPOUR-PRESSURE DETERMINATIONS.}

DIRECT measurement of the vapour-pressure of solutions for the estimation of molecular weights has never been much used, Raoult's barometric method being too cumbersome for general use. A simple apparatus for this purpose is, however, described by Mr. Robert Wright in the Journal of the Chemical Society for October. It consists of a flask (I 50 c.c.) and test-tube $(20 \mathrm{~cm} . \times 3 \mathrm{~cm}$.) connected by a delivery tube fused into well-fitting glass stoppers. This delivery tube is provided with a stopcock just above the flask; it reaches nearly to the bottom of the testtube, but does not pass through the stopper of the flask. The stopper to the test-tube is provided with an exit tube carrying a stopcock. To carry cut a vapour-pressure determination, a weighed quantity of the solute is placed in the test-tube, flask and tube are half-filled with solvent, and the apparatus connected together and evacuated by means of a filter-pump attached to the exit tube of the test-tube in order to boil all the air out of both solvent and solution. Expulsion of the air is facilitated by gently warming the flask. After exhaustion is complete both stopcocks are closed, and the apparatus left for two or three hours to attain the ordinary temperature. Then the tap above the flask is gently opened, and the extent to which the column of liquid in the delivery tube is depressed below the level of the solution in NO. 2622, VOL. IO4] the test-tube is a measure of the vapour-pressure. The observed depression must be corrected for capillarity. The test-tube is then removed and weighed in order to ascertain the mass of the solution, and if the latter is concentrated its density must be measured. As a solvent water is unsuitable, alcohol and carbon tetrachloride are satisfactory, but benzene cannot be used because of the action of its vapour on the taplubricant.

\section{EXPERIMENTS ON TRAIN RESISTANCE.}

$T O$ railway engineers Bulletin $x$ ro of the Uni1 versity of Illinois is of special interest, because it contains a report of some experiments on train resistance carried out by the experimental station of the University in co-operation with the Illinois Central Railway. Tests were made to measure the resistance of passenger trains in service up to speeds of seventy miles per hour. The main results are embodied in a set of curves. The peculiarity brought out by the experiments is that the resistance is not a function of the speed alone, but a function of the speed and the car-weight. The inference from the experiments is that, other things being equal, the heavier the car the less the resistance.

The results are likely to differ from those obtained by experiments on English railways, because the track is different, the standard of maintenance is probably different, and also the construction of the cars. Experiments on train resistance on British railways have been made by Sir John Aspinall. In these experiments it was found that the train resistance is a function of the speed and the length of the train. Probably if the Illinois experiments could be re-examined in terms of the length of the train, the Aspinall formula might be found to fit the data obtained, because increase in car-weight generally means increase in length of train; one is the function of the other.

Our American friends realise the national advan. tage to be gained by co-operation between university and railway. They have an experimental station organised and maintained by a university co-operating with a railway company in an experimental research. Similar relations might be hoped for between university and railway in this country. There is no doubt that both would gain considerably by mutual co-operation.

\section{THE EVOLUTION OF BOTANICAL RESEARCH.1}

A MEETING of the American Association in St. A Louis is of special interest to botanists. When this city was little more than a frontier town, Dr. George Englemann became one of its citizens. In spite of his duties as a successful physician, he became one of our greatest botanists; in fact, in the days when taxonomy was practically the whole of botany, and our virgin flora was being explored, the great American trio of botanists was Asa Gray (of Cambridge, Mass.), John Torrey (of New York), and George Englemann (of St. Louis). Englemann's distinction was that he published no general botanical works, but selected a series of the most difficult problems in taxonomy, and in a masterly way organised for us many perplexing groups. With these groups his name will always be associated. To a botanist, therefore, St. Louis means the home of George Englemann.

There is another association also for the botanist. St. Louis is the home of one of our great botanical

1 Presidential address delivered at the St. Louis meeting of the American Association for the Advancement of Science, December, 1919, by Prof. John M. Coulter. 
gardens, identified for those of us who are older with the name of Henry Shaw; but we are becoming accustomed to its later name, the Missouri Botanical Garden. Its plans and activities represent a fitting continuation of the spirit of Englemann and Shaw adapted to the progress of botanical science.

In consequence of these associations St. Louis may be said to have a botanical atmosphere, of which botanists are very conscious. We have the feeling, therefore, not of a visit, but of a home-coming.

A presidential address delivered to a group composed of investigators representing all the sciences, and including also those interested in science, should deal with some interest common to all. In my judgment, our common bond is interest in research; in fact, the major purpose of this association is to stimulate research by the personal contact of investigators. In selecting as my subject, therefore, the evolution of botanical research, I am assuming that the situation developed may apply in a general way to all scientific research.

My purpose is not to outline the history of botanical research, but rather to direct attention to certain evolutionary tendencies and to project them into the future. We are all familiar with the gradual historical development of different phases of botany, until botanists became segregated into many distinct groups, the only common bond being the use of plants for investigation. This segregation was for a time very complete, so that the interests of one group would not have been affected if none of the other groups had existed. This monastic phase of botany has subsided somewhat, not for all individuals, but for the subject in general. The different groups are coming into contact, and even interlocking, so that the science of botany bids fair to be recognised as an increasing synthesis rather than as an increasing disintegration. In connection with these gradual evolutionary changes, I wish to emphasise three tendencies which seem to me to be significant. As in all evolutionary progress, the tendencies may seem numerous, but the three I have selected seem to me to be especially prophetic of a new era of botanical research.

(I) One of the growing tendencies of botanical research is to attack problems that are fundamental in connection with some important practice. The outstanding illustration, of course, is the increasing attention given to the problems that underlie agriculture; but there are many other practices also which are embedded in botanical investigation. We all realise that this tendency was stimulated by the war; in fact, this has been the experience of all the sciences, more notable, perhaps, in physics and chemistry than in the other sciences, but a very obvious general result. This tendency is so strong at present that I do not believe it will ever subside, but it should be understood. There is no evidence that it is tending to diminish research, the sole purpose of which is to extend the boundaries of knowledge, which all of us must agree is the great objective of research. It merely means that experience developed in connection with an important practice has suggested fundamental problems the solution of which is just as important in extending the boundaries of knowledge as in 1lluminating some practice. In fact, among our most fundamental problems are those that have been suggested by experience. The injection of such problems among those not related to general experience is not to the detriment of the latter, but simply extends the range of research.

I have no sympathy with the artificial segregation of science into pure and applied science. All science is one. Pure science is often immensely practical, applied science is often very pure science, and between the two there is no dividing line. They are like the end-members of a long and intergrading series-very distinct in their isolated and extreme expression, but completely connected. If distinction must be expressed in terms where no sharp distinction exists, it may be expressed by the terms "fundamental" and "superficial." They are terms of comparison, and admit of every intergrade. The series may move in either direction, but its end-members must always hold the same relative positions. The first stimulus may be our need, and a superficial science meets it, but in so doing it may put us on the trail that leads to the fundamental things of science. On the other hand, the fundamentals may be gripped first, and only later find some superficial expression. The series is often attacked first in some intermediate region, and probably most of the research in pure science may be so placed; that is, it is relatively fundamental, but also relatively superficial. The real progress of science is away from the superficial towards the fundamental, and the more fundamental the results, the more extensive may be their superficial expression.

Not only are practical problems not a detriment to botanical science, they, incidentally, also strengthen its claim on public interest as a science that must be promoted. As an incidental result, I look with confidence to a future of far greater opportunity for research than has been, possible heretofore-research which must be increasingly fundamental and varied. Even if this were not true, my creed for science is that while its first great mission is to extend the boundaries of knowledge, that man may live in an ever-widening horizon, its second mission is to apply this knowledge to the service of man, that his life may be fuller of opportunity. From the point of view of science, the second may, be regarded as incidental to the first, but it is a very important incident, and really stimulates research. In short, I regard this so-called practical tendency in research as being entirely in the interest of research in general, in increasing the range of fundamental problems, in contributing a powerful stimulus, and in securing general recognition of the importance of research.

(2) A second tendency, which I regard as more important, is an increasing realisation of the fact that botanical problems are synthetic. Until recently a problem would be attacked from a single point of view, with a single technique, and conclusions reached that seemed as rigid as laws from which there is no escape. In plant morphology, for example-and I speak from personal experience-we described structures with no adequate conception of their functions. Plant physiologists, on the other hand, would describe functions with no adequate knowledge of the structures involved; while ecologists often described responses with no adequate knowledge of either structure or function. The same condition obtained in the other segregates of botany. We all recall the time when plant pathologists described and named pathogenic organisms and paid no attention to the disease, which, of course, is the physiological condition of the plant. In short, not only taxonomists, but all of us, were simply cataloguing facts in a kind of card-index unconsciously waiting for their co. ordination. This co-ordination has now begun, and is one of the strong tendencies which are certain to continue. The morphologist is beginning to think of the significance of the structure he is describing, and the physiologist to examine the structures involved in the functions he is considering; while the ecologist realises now that responses to environment which he has been cataloguing are to be interpreted only in terms of structure and function. In other words, around each bit of investigation, with its single

NO. 2622 , VOL. IO4] 
point of view and single method of attack, there is developing a perspective of other points of view and other methods of attack.

This does not mean a multiple attack on each problem by each investigator. We must remain morphologists, physiologists, and ecologists, each group with its special technique and special kind of data. But it does mean a better estimation of the results, a watchful interest in the possibilities of other methods of attack, a general toning-down of positiveness in conclusions. We all realise now that plants are synthetic, and that is quite a notable advance from that distant time when we thought of them only as objects subservient to laws of nomenclature. This increasing synthetic view is resulting in a proper estimate of problems. The data secured by each investigation constitute an invitation to further investigation. We have in mind the whole problem, and not scraps of information. In short, the synthetic view has developed about our problems the atmosphere in which they actually exist.

(3) A third tendency, which seems to me to be the most significant one, is the growing recognition of the fact that structures are not static-that is, inevitable to their last detail. As a morphologist I may recall to your memory the old method of recording the facts in reference to the development of such a structure as the embryo of seed-plants. Not only every cell-division in the ontogeny was recorded, but also the planes of every cell-division. The conception at the back of such records was that the programme of ontogeny was fixed to its minutest detail. It is probably true that such a structure is about as uniform in its development as any structure can be, but it has become evident now that many of the details recorded were not significant. Instead of cataloguing them as of equal value, we must learn to distinguish those that are relatively fixed from those that are variables.

In the same way, much of the older work in anatomy must be regarded as records of details of which the relative values were unknown. Even the structures involved in vascular anatomy are not static, but many a phylogenetic connection has been formulated on the conception of the absolute rigidity of such structures in their minutest detail. This conception has made it possible, of course, to develop as many static opinions as there are variables in structure.

Perhaps the greatest mass of details has been accumulated by the cytologists in connection with their examination of the machinery of nuclear division and nuclear fusion. In no other field has the conception of the rigidity of the structures involved become more fixed, even to the minutest variation in form and position. Of course, we all realise that any field of investigation must be opened up by recording all the facts obtained, but we must realise that this is only the preliminary stage. The time has come when even the recorded facts of cytology are being estimated on the basis of relative values-that is, the inevitable things are being differentiated from the variables.

The same situation is developing in the field of genetics. We all recall the original rigidity of the so-called laws of inheritance. It was natural to begin the cultivation of this field with the conception that the programme of heredity is immutable, and that definite -structures are inevitable, no matter what the conditions may be. There was probably more justification for this conception in this field, on the basis of the early investigations, than in any other, but experience has begun to enlarge the perspective wonderfully. The rapidly accumulating facts are becoming so various that consistent explanations NO. 2622 , VOL. IO4] require a high degree of mental agility. More fundamental, however, is the recognition of the fact that the problem of heredity involves not only germinal constitution, which gives such rigidity as there is, but also the numerous factors of environment. In other words, such problems have become synthetic in the highest degree, making possible results that are anything but static.

In considering these illustrations of the tendency to recognise that facts are not all pigeon-holed and of equal value, it is becoming more and more obvious that. our botanical problems are, in general, the application of physics and chemistry to plants; that lazes, when we really discover them, are by definition static, but that their operation results in anything but static structures. In other words, structure must respond to law, but the particular law that is gripping the situation may be one of many.

With such evolutionary tendencies in mind, what is the forecast for botanical research? I wish to direct attention to three important features that seem certain to characterise it:

(I) It will be necessary for the investigator who wishes to have a share in the progress of the science, rather than merely to continue the card-catalogue assembling of random data, to have a broader botanical training than has seemed necessary heretofore. Our danger has been that the cultivation of a special technique, which, of course, is necessary, is apt to limit the horizon to the boundary of that technique. In some cases the result to the investigator has been more serious than limiting his horizon; it has led him to discredit other methods of attack as of little importance. In case this attitude is associated with the training of students, it is continued and multiplied by pedigree culture. The product of certain laboratories is recognised as of this type, and it is out of line with the evident direction of progress.

This demand of the future does not mean that one must specialise less than formerly. It is obvious that, with the increasing intricacy of problems and the inevitable development of technique, we must specialise more than ever. What the new demand means is not to specialise less, but to see to it that every speciality has developed about it a botanical perspective. In other words, instead of an investigator digging himself into a pit, he must do his work on a mountain-top. This secures some understanding and appreciation of other special fields under cultivation, some of which will certainly interlock with his own field. To meet this situation will demand more careful attention to the training of investigators than it has received. Interested, and even submerged, in our own work, as we must be, still we must realise that the would-be investigator must develop his atmo sphere as well as his technique, or he will remain medieval.

To be more concrete, the morphologist in the coming days must appreciate the relation that physiology and ecology hold to his own field. This is far from meaning that he must be trained in physiological and ecological investigation, but he must know its possibilities. The same statement applies in turn to the physiologist and ecologist, and so on through the whole list of specialities.

This first forecast of the future applies to the necessary training of investigators rather than to investigation itself.

(2) A second important feature that is sure to be included in the botanical investigation of the future is co-operation in research. During the last few years the desirability of co-operation has been somewhat stressed, and perhaps the claims for it have been urged somewhat unduly. This was natural when 
we were desiring to secure important practical results as rapidly as possible. It opened up, however, the possibilities of the future. No one questions that individual research, to contrast it with co-operative research, must continue to break the paths of our progress. Men of ideas and of initiative must continue to express themselves in their own way, or the science would come to resemble field cultivation rather than exploration. It is in this way that all our previous progress has been made. The new feature is that individual research will be increasingly supplemented by co-operative research. There are two situations in which co-operative research will play an important rôle.

The more important situation is the case of a problem the solution of which obviously requires two or more kinds of special technique. There are many problems, for example, which a morphologist and a physiologist should attack in co-operation, because neither of them alone could solve it. Two detached and unrelated papers would not meet the situation. Our literature is burdened with too many such contributions now. The one technique must be a continual check on the other during the progress of the investigation. This is a very simple illustration of what may be called team-work. It is simply a practical application of our increasing realisation of the fact that problems are often synthetic, and therefore involve a synthetic attack.

Another simple illustration may be suggested. If taxonomists and geneticists should work now and then in co-operation, the result might be either fewer or more species, but, in any event, they would be better species. The experience of botanists can suggest many other useful couplings in the interest of better results. In the old days some of you will recall that we had investigations of soil bacteria unchecked by any work in chemistry, and side by side with this were investigations in soil chemistry unchecled by any work with soil bacteria.

lerhaps the most conspicuous illustration of discordant conclusions through lack of co-operation, so extreme that it may be called'lack of co-ordination, may be found in the fascinating and baffling field of phylogeny. To assemble the whole plant kingdom, or at least a part of it, in evolutionary sequence has been the attempt of a considerable number of botanists, and no one of them as yet has taken into consideration even all the known facts. There is the palæobotanist who rightly stresses historical succession, with which, of course, any evolutionary sequence must be consistent, but cannot be sure of his identifications; and still less of the essential structures involved. History is desirable, but some real knowledge of the actors who make history is even more desirable.

Then there is the morphologist, who stresses similarity of structures, especially reproductive structures, and leaves out of sight not only accompanying structures, but also historical succession.

Latest in the field is the anatomist, especially the vascular anatomist, who compares the vascular structures in their minutest detail, and loses sight of other important factors in any evolutionary succession.

Apparently no one as yet has taken all the results from all fieldis of investigation and given us the result of the combination. In other words, in phylogeny we have had single-track minds. This has been necessary for the accumulation of facts, but unfortunate in reaching conclusions.

This is but a picture of botanical investigations in general as formerly conducted, and it seems obvious that co-operative research will become increasingly common as co-operation is found to be of advantage.
The second situation in which co-operative research will play an important role is less important than the first, but none the less real. It must be obvious to most of us that our literature is crowded with the records of incompetent investigations. Not all who develop a technique are able to be independent investigators. They belong to the card-catalogue class. They are not even able to select a suitable problem. We are too familiar with the dreary rehearsal of facts that have been told many times, the only new thing, perhaps, being the material used; and even then the result might have been foretold. It is unfortunate to waste technique and energy in this way, and the only way to utilise them is through co-operative research, for which there has been a competent initiative, and in the prosecution of which there has been a suitable assignment of parts. In my judgment, this is the only way in which we can conserve the technique we are developing and make it count for something. I grant that the product of such research is much like the product of a factory, but we may need the product.

In one way or another co-operative research will supplement individual research. Individuals, as a rule, 'will be the pioneers; but all cannot be pionecrs. After exploration there comes cultivation, and much cultivation will be accomplished by co-operation.

(3) The most important feature that will be developed in the bctanical investigation of the future is experimental control. Having recognised that structures are not static, that programmes of development are not fixed, and that responses are innumerable, we are no longer satisfied with the statement that all sorts of variations in results occur. We must know just what condition produced a given result. 'This questioning as to causes of variable results first took the form of deduction. We tried to reason the thing out.

A conspicuous illustration of this situation mav be obtained from the history of ecology. Concerned with the relation of plants to their environment, deductions became almost as numerous as investigators. Even when experimental work was begun, the results were still vague because of environment. Finally, it became evident that all the factors of environment must be subjected to rigid experimental control before definite conclusions could be reached.

What is true of ccology is true also of every phase of botanical research. For example, I happened to be concerned with materials that showed an occasional monocotyledonous embryo with two cotyledons, while most of the embryos were normal. The fact, of course, was important, for it connected up mono cotyledons and dicotyledons in a very suggestive way, and also opened up the whole question of cotyledony. Important as the fact was, much more important was the cause of the fact. We could only infer that certain conditions might have resulted in a dicotyledonous embryo in a monocotyledon; but it was a very unsubstantial inference. That problem will never be solved until we learn to control the conditions and produce dicotyledonous embryos fróm monocotyledons at will, or the reverse. Comparison and inference must be replaced by experimental control, just as in the history of organic cvolution the method shifted from comparison and inference to experimental control. It will be a slow evolution, and most of our conclusions will continue to be inferences, but these inferences will eventually be the basis of experiment. In fact, most of our conclusions are as vet marking time until a new technique enables us to move forward.

These illustrations from ecology and morphology represent simple situations as compared with the demands of cytology or genetics, but the same need 
for experimental control is a pressing one in those fields. The behaviour of the complex mechanism of the cell is a matter of sight, followed by inference, when we know that invisible factors enter into the performance. How the cell programme can ever be brought under experimental control remains to be seen, but we must realise that in the meantime we are seeing actors without understanding their action. In fact, we are not sure that we see the actors; the visible things may be simply a result of their action. The important point is to keep in mind the necessary limitations of our knowledge, and not mistake inference for demonstration.

Even more baffling is the problem of adequate experimental control in genetics. We define genetics as breeding under rigid control, the inference being that by our methods we know just what is happening. The control is rigid enough in mating individuals, but the numerous events between the mating and the appearance of the progeny are as yet beyond the reach of control. We start a machine and leave it to its own guidance. The results of this performance, spoken of as under control, are so various that many kinds of hypothetical factors are introduced as tentative explanations. There is no question that this is the best that can be done at present, but it ought to be realised that as yet no real experimental control of the performance has been devised. The initial control, followed by inferences, has developed a wonderful perspective, but a method of continuous control has yet to come.

Having considered the conspicuous evolutionary tendencies of botanical research and their projection into the future, it remains to consider the possible means of stimulating progress. It will not be accomplished by increasing publication. It is probably our unanimous judgment that there is too much publication at the present time. What we need is not an increasing number of papers, but a larger percentage of significant papers. This goes back to the selection of problems, assuming that training is sufficient. A leader is expected to select his own problems, but we are training an increasing armv of investigators, and the percentage of leaders is growing noticeably less. There ought to be some method by which botanists shall agree upon the significant problems at any given time in the various fields of activity, so that strch advice might be available. It is certainly needed.

I realise that our impulse has been to treat a desirable problem as private property, upon which no trespassing is allowed. Of course, common courtesy allows an investigator to work without competition, but the desirable problems are still more numerous than the investigators, and we must use all our investigative training and energy in doing the most desirable things. There need be no fear of exhausting problems, for every good problem solved is usually the progenitor of a brood of problems. We shall never multiply investigators as fast as our investigations multiply problems. In the interest of science, therefore, we should pool our judgment, and indicate to those who need it the hopeful directions of progress.

Not only is there dissipation of time and energy in the random selection of problems, there is also wastage in investigative ability. Every competent investigator should have the opportunity to investigate. The pressure of duties that too often submerge those trained to investigate is a tremendous brake upon our progress. I am not prepared to suggest a method of meeting this situation, but the scientific fraternity in some way should press the point that one who is able to investigate should have both time and opportunity. A university regulation, with which we are all too familiar, which requires approximately NO. 2622 , VOL. IO 4 the same hours of ail its staff, whether they are investigators or not, should be regarded as medieval.

In conclusion, speaking not merely for botanical research, but for all scientific research, it has now advanced to a stage which promises unusually rapid development. The experience of the recent years has brought science into the foreground as a great national asset. It should be one of the functions of this association to see to it that full advantage is taken of the opportunity offered by the present evolutionary stage of research and public esteem. We must choose between inertia and some display of aggressive energy.

\section{UNIVERSITY AND EDUCATIONAL INTELLIGENCE.}

London.-The faculty of medicine has elected Dr. H. L. Eason to be its representative on the Senate in succession to Sir Cooper Perry, who has resigned on his appointment to the post of Principal Officer of the University; and the faculty of science has elected Prof. L. N. G. Filon to be its representative on the Senate in succession to Prof. G. A. Buckmaster, who has resigned on his appointment to the chair of physiology in the University of Bristol.

Prof. T. Loveday, professor of philosophy at Armstrong College, Newcastle-upon-Tyne, has been appointed principal of Southampton University College in succession to Dr. Alex Hill, resigned.

Mr. A. V. Hill, F.R.S., fellow of King's College, late fellow of Trinity College, and lecturer in physiology in the University of Cambridge, has been appointed to the vacant chair of physiology in the University of Manchester.

Girton College, Cambridge, has received a gift of ro,oool., the capital and interest of which are to be applied during the next twenty' years for the encouragement of scientific research by women in mathematical, physical, and natural sciences.

LT:-Col. P. S. LeLEAN, professor of hygiene, Royal Army Medical College, will distribute prizes and certificates at the Sir John Cass Technical Institute on Tuesday, February 3 , and will give an address on applied science in gas warfare.

ON Wednesday, January 2I, Mr. E. Wyndham Hulme was presented by the Patent Office Library staff with an illuminated address, bound in morocco, recording their appreciation of his work as librarian during the last twenty years. We understand that $\mathrm{Mr}$. Hulme will continue his editorial supervision of the "Subject Index to Periodicals" published by the Library Association. Mr. Hulme has been succeeded in his office by Mr. Allan Gomme, son of the late Sir Laurence Gomme, and formerly an assistant examiner in the Patent Office.

THE statement of the Rhodes Scholarships Trust for the year rolg shows that the number of scholars actually in residence for either the whole or some part of the academic year I9I8-I9 was eighty-seven, viz. sixty-six Colonials and twenty-one Americans. Of these, thirty-one came into residence for the first time. There were also in residence nine ex-scholars, of whom five were Colonials and four Americans. In the United States the elections this year have been held under new conditions. In the first place, there has been no qualifying examination. The competition has been open, limited only by the fact that, in any given State, no one institution could be represented in the competition by more than a small number of 